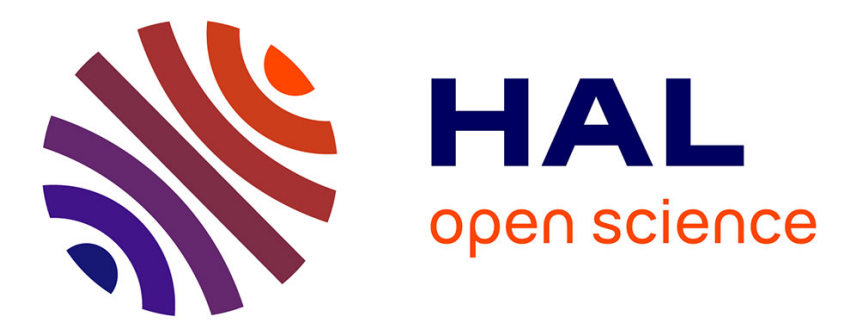

\title{
Second Harmonic Generation in Sodium Tantalum Germanate Glasses by Thermal Poling
}

\author{
Gael Poirier, Marc Dussauze, Vincent Rodriguez, Frédéric Adamietz, Lara
} Karam, Thierry Cardinal, Evelyne Fargin

\section{> To cite this version:}

Gael Poirier, Marc Dussauze, Vincent Rodriguez, Frédéric Adamietz, Lara Karam, et al.. Second Harmonic Generation in Sodium Tantalum Germanate Glasses by Thermal Poling. Journal of Physical Chemistry C, 2019, 123 (43), pp.26528-26535. 10.1021/acs.jpcc.9b08221 . hal-02392661

\section{HAL Id: hal-02392661 https://hal.science/hal-02392661}

Submitted on 7 Jul 2020

HAL is a multi-disciplinary open access archive for the deposit and dissemination of scientific research documents, whether they are published or not. The documents may come from teaching and research institutions in France or abroad, or from public or private research centers.
L'archive ouverte pluridisciplinaire HAL, est destinée au dépôt et à la diffusion de documents scientifiques de niveau recherche, publiés ou non, émanant des établissements d'enseignement et de recherche français ou étrangers, des laboratoires publics ou privés. 


\section{Second harmonic generation in sodium tantalum}

germanate glasses by thermal poling

Gael Poirier $\left.{ }^{1 *}\right)$, Marc Dussauze $^{2}$, Vincent Rodriguez², Frédéric Adamietz ${ }^{2}$, Lara Karam $^{2}$, Thierry Cardinal ${ }^{3}$ and Evelyne Fargin ${ }^{3}$.

${ }^{1}$ Grupo de Química de Materiais, Universidade Federal de Alfenas, Campus de Poços de Caldas, Poços de Caldas-MG, Brazil

${ }^{2}$ Institut des Sciences Moléculaires, UMR 5255, Université de Bordeaux, 351 cours de la Libération, 33405 Talence Cedex, France.

${ }^{3}$ Institut de Chimie de la Matière Condensée de Bordeaux, Université de Bordeaux, 87 Avenue du Dr Schweitzer, F-33608, Pessac, France.

(*) Corresponding author.

E-mail: gael.poirier@unifal-mg.edu.br

Mail address: Instituto de Ciência e Tecnologia, Campus de Poços de Caldas - Caldas-MG, Brazil - CEP 37715-400 


\section{Abstract}

Structure, linear and nonlinear optical properties of glasses in the ternary system $(90-x) \mathrm{GeO}_{2}-10 \mathrm{Na}_{2} \mathrm{O}-\mathrm{xTa}_{2} \mathrm{O}_{5}$ have been investigated. These glasses exhibit a wide transparency window from $350 \mathrm{~nm}$ to $5500 \mathrm{~nm}$ and refractive index ranging from 1,78 to 1,93 . Upon a thermal poling treatment under nitrogen atmosphere using increasing poling voltages, SHG quantitative measurements were performed and have confirmed the electro-optical origin of the second order optical responses, $\chi^{(2)}$ values ranging from $0,06 \mathrm{pm} / \mathrm{V}$ to $0,3 \mathrm{pm} / \mathrm{V}$ were obtained depending on the poling conditions and glass composition. SHG/Raman correlated microscopy measurements allowed to identify the structural changes within the poled layer and pointed out that sodium depletion lead to a more connected glass network through cross-linking bonds such as Ge-O-Ge and Ta-O-Ta bonds. A deviation from a pure electro-optical second order response is observed for the highest poling voltage. In this particular case, a linear optical birefringence and a structural $\chi^{(2)}$ might have to be taken in account to describe accurately the polarized layer optical properties.

Keywords: glass, germanate, tantalum, thermal poling, second harmonic generation. 


\section{1 - Introduction}

Alkali niobium or tantalum germanate glasses are interesting glassy materials for optical applications since they combine high refractive index and wide transparency window, which make them suitable for applications in the middle infrared. Modification of the germanate network by the transition metal oxide (TMO) incorporation $\left(\mathrm{Nb}_{2} \mathrm{O}_{5}\right.$ or $\left.\mathrm{Ta}_{2} \mathrm{O}_{5}\right)$ also results in key luminescent materials since rare earth ions (RE) are preferentially located in TMO-rich environments. [1-3] Therefore, RE luminescent properties are strongly dependent of the TMO content and crystallization state of the sample since alkali tantalate or niobate bronze-like crystalline phases can be precipitated in these samples and result in transparent glass-ceramics [1-3]. For example, near infrared or visible emission obtained by up-conversion can be easily tuned in $\mathrm{Er}^{3+}$ doped samples by controlling the composition and degree of crystallinity.

On the other hand, thermal poling is a very promising treatment for local modification of optical properties in glasses because of (i) a surface depletion of alkali ions under the anode and (ii) a permanent static electric field embedded in under the glass surface. [4-6] This depletion layer in mobile cations exhibits a refractive index modification which can be useful for micro-optics fabrication. [7, 8, 9] whereas the electrical space charge allows for a second order susceptibility $\chi^{(2)}$ which depends on the magnitude of the implanted electric field (Eint) and the third order optical susceptibility $\left(\chi^{(3)}\right)$ according to the relation $\chi^{(2)}=3 . \chi^{(3)}$. Eint, known as the EFISH model (Electric Field Induced Second Harmonic) [10-12]. Such modifications are useful for optical applications such as wavelength conversion and electro-optical devices [13-14]. Therefore, thermal poling effects were 
intensively investigated in several oxide glasses such as silicate [10-12, 15-17], phosphate [18-21], or tellurite compositions [22-24] as well as chalcogenide glasses [25-27]. However, despite the well-known interesting optical properties of germanate glasses, their nonlinear second order optical properties induced by thermal poling were comparatively hardly studied [28-29].

Based on these considerations, this work focused on the thermal poling of sodium tantalum germanate glasses in the ternary system $(90-x) \mathrm{GeO}_{2}-10 \mathrm{Na}_{2} \mathrm{O}-$ $\mathrm{xTa}_{2} \mathrm{O}_{5}$ with $\mathrm{x}=15$ and 20 . The influence of poling voltage and tantalum oxide content on the induced second order nonlinear susceptibility $\chi^{(2)}$ was investigated. Second Harmonic generation (SHG) and Raman mapping were used to correlate the optical and structural modifications of these glasses in the thermally poled layer under the anode.

\section{2 - Experimental Procedure}

The glass samples in the ternary system $(90-x) \mathrm{GeO}_{2}-10 \mathrm{Na}_{2} \mathrm{O}-\mathrm{xTa} \mathrm{O}_{5}$ with x=15 and 20 (Table 1) were prepared from reagent grade $\mathrm{GeO}_{2}$ 99,9\%, $\mathrm{Ta}_{2} \mathrm{O}_{5}$ $99,9 \%$ and $\mathrm{Na}_{2} \mathrm{CO}_{3}$ (from Sigma Aldrich Corp.), previously dried in oven at $105^{\circ} \mathrm{C}$ for $12 \mathrm{~h}$. Reagents were weighed in analytical balance for a $30 \mathrm{~g}$ total batch, mixed and ground in agate mortar, transferred to a platinum crucible and heated from room temperature to $1500^{\circ} \mathrm{C}$ using a heating rate of $5^{\circ} \mathrm{C} / \mathrm{min}$. Melting at this temperature was maintained for 2 hours to ensure homogeneity. Since glass transition temperatures were determined by DSC around $720^{\circ} \mathrm{C}$ for GNT15 and $750^{\circ} \mathrm{C}$ for GNT20, the melt was cooled in cold water for 5 seconds and immediately introduced in a furnace at $700^{\circ} \mathrm{C}$ for annealing during 12 hours to minimize 
mechanical stress before a slow cooling to room temperature. After being removed from the crucible, the glass samples were cut and optically polished on both sides using alumina suspensions with decreasing particle sizes of $20 \mu \mathrm{m}, 9 \mu \mathrm{m}$ and $3 \mu \mathrm{m}$ for a final sample size of $25 \mathrm{~mm}$ in diameter and a thickness of $1 \mathrm{~mm}$ as shown in Figure 1(a).

The optical window has been reconstructed from transmittance spectra obtained in the UV-Vis-NIR between $200 \mathrm{~nm}$ and $2 \mu \mathrm{m}$ using a double beam Agilent Cary 5000 spectrophotometer and transmittance spectra in the infrared between $2 \mu \mathrm{m}$ and $10 \mu \mathrm{m}$ using a FTIR Bruker Equinox 55 spectrophotometer. Refractive indices were obtained by the Brewster angle technique at $405 \mathrm{~nm}, 532 \mathrm{~nm}, 639 \mathrm{~nm}$, 934nm, 1310nm and 1550nm. [30] Thermal poling was performed on polished glasses GNT15 and GNT20 at 265ํㅡ $\mathrm{C}$ under flowing nitrogen atmosphere for 60 min. The cathode was constituted of a n-doped silicon wafer and a $150 \mu m$-thick borosilicate glass in contact with the sample surface. First poling tests on these sodium tantalum germanate glasses were performed using the same n-doped silicon wafer as the anode but this wafer could not be removed after the thermal poling treatment and strongly "stuck" to the glass surface due to anodic bonding mechanisms. For this reason, ITO thin films deposited on a borosilicate glass were used as the anodic material and electric contact was ensured by covering the ITOfree surface and sides with a silver conductive paint. The anode area of approximately $35 \mathrm{~mm}^{2}$ was maintained constant for all poling experiments. Different dc electric field voltages ranging from $900 \mathrm{~V}$ to $2250 \mathrm{~V}$ were applied for thermal poling as described in Table 1.

Correlative micro-Raman and micro-SHG measurements were recorded in backscattering mode on a modified micro-Raman spectrometer HR800 
(Horiba/Jobin Yvon). A continuous wave laser operating at 532nm is used for Raman and a picosecond pulsed laser at $1064 \mathrm{~nm}$ is used for micro-SHG measurements. Typical resolution used for Raman is $2.5 \mathrm{~cm}^{-1}$. Measurements were carried out on the cross section of the poled glasses. The objective used was a $100 \mathrm{x}$ long working distance with a numerical aperture of 0.5 from Mitutoyo allowing for a resolution in the X-Y plane of $0.8 \mu \mathrm{m}$ for Raman measurements. Note the resolution for micro-SHG mapping is naturally improved as a two photon excitation process is involved.

The SHG response of the glasses after thermal poling was quantified using the Maker fringes technique. The incident laser is a $1550 \mathrm{~nm}$ nanosecond laser operating at $30 \mathrm{~Hz}$ with a maximum pulse energy of $100 \mu \mathrm{J}$ during a 20 ns pulse and with a spot size of $100 \mu \mathrm{m}$. Two types of scan are measured in transmission mode with this set-up. The first one is known as a $\theta$-scan as the measurement is made as a function of incident angle $(\theta)$ with fixed incident and harmonic polarization p (horizontally) or s (vertically). The second type of scan is a $\psi$-scan where the incident angle is fixed and so is the polarization at the analyzer ( $\mathrm{s}$ or p). The measurement is done as a function of the polarization state of the incident beam (linear, circular or elliptical). Absolute values of the second order susceptibilities were obtained using a quartz z-cut plate as a reference for the calibration of the SHG setup. A general matrix formulation of linear and nonlinear optical responses, described previously by one of us, has been used to simulate the data [31].

\section{3 - Results}


Transparent and homogeneous glass samples were obtained in the ternary system $(90-x) \mathrm{GeO}_{2}-10 \mathrm{Na}_{2} \mathrm{O}-\mathrm{xTa}_{2} \mathrm{O}_{5}$ with $\mathrm{x}=15$ and 20 (Figure 1(a)). Previous studies pointed out that, for a constant alkali oxide content of $10 \mathrm{~mol} \%$, these compositions are at the limit of the glass forming domain concerning the $\mathrm{Ta}_{2} \mathrm{O}_{5}$ content [1]. As already described, these glasses are interesting materials because of their wide optical window from $350 \mathrm{~nm}$ to $5,5 \mu \mathrm{m}$ as well as their relatively high refractive indices as presented in Figure 1(b) and 2 respectively. The absorption band observed at around $2750 \mathrm{~nm}$ is attributed to hydroxyl group impurities. It has already been demonstrated that tantalum incorporation in oxide formers improves rare earth luminescent properties in the visible and near infrared by lowering the phonon energy.[32] It is also expected that tantalum would enhance the nonlinear optical properties of these glasses because of a higher overall polarizability. Based on these considerations, these materials are promising for optical applications in the middle infrared, justifying this work devoted to the investigation of surface optical modifications by thermal poling as a function of the applied voltage and glass composition. Thus, glass composition GNT15 was poled using voltages of $900 \mathrm{~V}, 1350 \mathrm{~V}$ and $2250 \mathrm{~V}$ and composition GNT20 was poled at 1350V. The thicknesses of the poled layers were estimated by SHG mapping along the anode cross section as presented in a SHG-map for the sample GNT15-2250 in Figure 3(a) and SHG intensity profiles for the GNT15 samples poled with different applied voltages in Figure 3(b). The poled layers are uniform ranging from $5.5 \mu \mathrm{m}$ for the highest voltage to $2.5 \mu \mathrm{m}$ for the lowest. One can observe that from 900 to $1350 \mathrm{~V}$ the thickness of the SHG active layer does not change significantly whereas it is more than doubled when the voltage increases to $2250 \mathrm{~V}$. 
In order to investigate the structural changes occurring in the poled layer, microRaman measurements were performed at the same positions by taking advantage of a correlative SHG/Raman microscope. The results obtained for the sample GNT15-2250 are shown in Figure 4. Important changes could be detected in the relative intensity of several Raman modes between the SHG active layer and the pristine glass, as better seen in the Raman intensity difference spectrum presented in Figure 4(b). In particular, three important Raman modes centered at $430 \mathrm{~cm}^{-1}$, $715 \mathrm{~cm}^{-1}$ and $800 \mathrm{~cm}^{-1}$ (labeled band 1, 2 and 3 in Figure 4) were investigated and the difference spectrum clearly pointed out that the intensity of these Raman modes is sensitive to the thermal poling treatment. Raman mapping experiments are also presented in Figure 4 for these three Raman modes. By comparison, it appears that the structural changes detected are correlated with the SHG active layer shown in Figure 3. The first Raman mode at $430 \mathrm{~cm}^{-1}$ has been often reported in alkali germanate glasses and is commonly attributed to Ge-O-Ge bridging bonds in four-membered rings of $\mathrm{GeO}_{4}$ tetrahedra [33,34]. Its increase in relative intensity after thermal poling suggests a structural rearrangement of the glass network where the sodium migration out of the poled layer promotes the formation of more bridging Ge-O-Ge bonds, probably originated from the terminal Ge-0- bonds stabilized by $\mathrm{Na}^{+}$ions in the untreated glass. Another interesting feature is related with the Raman band (labeled band 2 in Figure 4) centered at $715 \mathrm{~cm}^{-1}$ and often attributed to $\mathrm{TaO}_{6}$ units in an amorphous three-dimensional $\mathrm{TaO}_{6}$ network, which was already reported in amorphous tantalum oxide thin films as well as tantalum-containing glasses with high $\mathrm{Ta}_{2} \mathrm{O}_{5}$ contents $[35,36]$. As observed in Figure 4, its relative intensity slightly increases after thermal poling, suggesting that such three-dimensional $\mathrm{TaO}_{6}$-rich regions are promoted after 
sodium depletion, once again in agreement with a structural model in which glass network connectivity is enhanced after thermal poling as a way to balance the

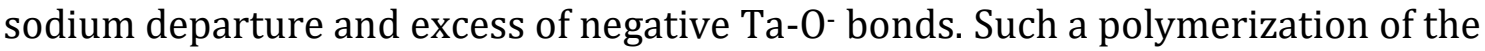
glassy network should also involed a loss of oxygen as observed in oxide poled glassy systems [28]. Finally, the third Raman band useful to understand the overall structural changes ocurring after poling is centered at $800 \mathrm{~cm}^{-1}$ (band 3 in Figure 4). Since this Raman band is detected as soon as $\mathrm{Ta}_{2} \mathrm{O}_{5}$ is added to alkali germanate glasses even for low contents and is also detected in other $\mathrm{Ta}_{2} \mathrm{O}_{5}$ containing oxide glass formers $[37,38]$, this signal is assumed to be related with Ta-O stretching modes in isolated $\mathrm{TaO}_{6}$ units distributed inside the covalent germanate network but not bonded to other $\mathrm{TaO}_{6}$ octahedra. Its relative decrease in intensity was not expected based on previous interpretations related with higher network connectivity after treatment but such behavior suggests that the structural changes after thermal poling, although promoting the formation of bridging bonds to compensate negative charges of terminal $\mathrm{Ge}^{-} \mathrm{O}^{-}$and $\mathrm{Ta}-\mathrm{O}^{-}$, do not favor mixed Ge-O-Ta bridging bonds but only Ge-O-Ge and Ta-O-Ta linkagesBased on this hypothesis, it seems that this structural rearrangement following thermal poling can be seen as an initial stage of amorphous phase separation, forming highly connected $\mathrm{GeO}_{2}$ and $\mathrm{Ta}_{2} \mathrm{O}_{5}$ rich regions.

The macro-SHG measurements are presented for the four samples in Figure 5. Figure 5(a) refers to the SHG intensity as a function of the incident angle using a P polarization for both the incident beam and detected SHG ( $\theta$-pp scan). This experiment is commonly known as the Maker fringe measurement. We observe only one fringe for all the samples which is due to SHG active layer thicknesses shorter than the coherence length of the propagating media. This is confirmed by 
the micro SHG characterization depicted in Figure 3 and the measured refractive indices in Figure 2, which give for both compositions coherence length values of $7.75 \pm 1 \mu \mathrm{m}$ for an incident wavelength at $1550 \mathrm{~nm}$. Considering efficiency of the NLO responses, the SHG intensity increased by a factor of 15 when the poling voltage increased from $900 \mathrm{~V}$ to $1350 \mathrm{~V}$ and by a factor of 1.5 for voltage from $1350 \mathrm{~V}$ to $2250 \mathrm{~V}$. Increasing the $\mathrm{Ta}_{2} \mathrm{O}_{5}$ content from 15 to $20 \mathrm{~mol} \%$ increased the SHG response by a factor 1.8 for the same poling conditions.

To go in more details in the poling induced- $\chi^{(2)}$ tensor characterization, we have processed SHG-polarization scans (called $\Psi$-scans). Figure 5(b) and (c) presents the SHG intensity versus the incident polarization state, $\Psi$, for a P and S polarized SHG measured intensity (respectively called $\Psi$-p and $\Psi$-s scans). These SHG polarization scans were first simulated considering an EFISH mechanism (Electric Field Induced Second Harmonic): Considering that SHG is only due to interaction of the static electric field implanted under the anode with the third order optical susceptibility, according to the relation $\chi^{(2)}=3 \cdot \chi^{(3)}$.Eint. The simplified $3 \times 6$ SHG tensor treated in the $C_{\infty v}$ local symmetry contains only two non-zero components $\chi^{(2)_{z z z}}$ and $\chi^{(2)_{z x x}}$ with a unique value since the EFISH model results in a fixed ratio $\chi^{(2)_{z z z}} / \chi^{(2)_{z x x}}=3$. Then, the SHG data can be fitted using only one adjustable value $\left(\chi^{(2)_{z z z}}\right)$ as refractive index of the glass and thickness of the poled layer are determined by independent measurements given in Figure 2 and Figure 3. Under these fitting conditions, experimental SHG signals could be fitted with very good agreement for all poling done at 900 and $1350 \mathrm{~V}$, as exemplified in Figure 5(b) and (c) for GNT-1350. Slight discrepancies appear between EFISH simulation and experimental data for the sample GNT15-2250 poled with the 
highest voltage, this particular case being considered in the discussion part. Under these assumptions, second order susceptibilities were estimated for the samples as a function of the poling voltage (900V, 1350V and 2250V for sample GNT15) and composition (1350V for samples GNT15 and GNT20) with $\chi^{(2)}$ values resumed in Table 1. As expected from the observations, increasing poling voltage in glass composition GNT15 promotes a more intense SHG signal and a higher induced $\chi^{(2)}$ value from $0.06 \mathrm{pm} / \mathrm{V}$ for poling at $900 \mathrm{~V}$ to $0.23 \mathrm{pm} / \mathrm{V}$ when poled at $2250 \mathrm{~V}$; increasing $\mathrm{Ta}_{2} \mathrm{O}_{5}$ content from 15 to $20 \%$ lead to higher second order susceptibilities (from 0,2 to $0,3 \mathrm{pm} / \mathrm{V}$ ).

\section{4- Discussion}

The poling-induced $\chi^{(2)}$ values obtained for these $\mathrm{Na}_{2} \mathrm{O}-\mathrm{GeO}_{2}-\mathrm{Ta}_{2} \mathrm{O}_{5}$ glasses should be compared to other heavy oxide poled glasses reported in the literature. In this study, for the two samples GNT15-1350 and GNT20-1350, the SHG signals have been successfully characterized by an EFISH model. As the SHG microscopy characterization has shown similar thicknesses of polarized layers (table 1), one can expect a similar magnitude of embedded static fields for these two samples. It denotes that the higher second order optical susceptibilities observed upon increasing $\mathrm{Ta}_{2} \mathrm{O}_{5}$ content from 15 to 20 mol\% should be related to an expected higher third order susceptibility of the GNT20 glass. By comparison, in sodoniobium borophosphate glasses, $\chi^{(2)}$ coefficients of 0.16 and $4.2 \mathrm{pm} / \mathrm{V}$ have been respectively reported for 35 and $48 \mathrm{~mol} \%$ of $\mathrm{Nb}_{2} \mathrm{O}_{5}$. [19] In the system $\mathrm{Na}_{2} \mathrm{O}-\mathrm{GeO}_{2}-$ $\mathrm{Nb}_{2} \mathrm{O}_{5}, 0.6 \mathrm{pm} / \mathrm{V}$ were quantified for a bulk glass containing $28 \mathrm{~mol} \%$ of niobium pentoxide.[28] It shows that if we consider the amount of $\mathrm{Nb}$ or Ta incorporated in 
the glass matrix, thermally poled niobate and tantalate bulk glasses exhibit comparable second order optical susceptibilities. The key limitation in these glassy systems is the amount of $\mathrm{Nb}$ or Ta oxides which could be introduced without crystallization of bulk glasses under cooling. To better compare these $\chi^{(2)}$ values, if we consider an EFISH model, additional $\chi^{(3)}$ measurements are needed. The third order optical susceptibilities in such systems depends on both the number of $\mathrm{Nb}$ or Ta atoms per volume and on the structural arrangement of the niobate or tantalate networks. [39-41] In addition, one should not neglect the effects of poling on the glass structure influencing its first and third order optical properties. The change of density, induced by mobile cations depletion, is one of the most important macroscopic factors as revealed by previous studies on the refractive index changes in other poled glassy systems. [7, 42] The second point concerns the polarizability of the rearranged glassy structure. In this study, Raman analysis of the poled layer has revealed some indications of an amorphous phase separation, forming highly connected $\mathrm{Ta}_{2} \mathrm{O}_{5}$ rich regions. This assumption is mainly supported by the relative decrease of a Raman signal around $800 \mathrm{~cm}^{-1}$, well described in previous works as related to isolated $\mathrm{TaO}_{6}$ units inserted the oxide glass former. $[37,38]$ On the other hand, polymerization takes place under poling in the germanate and tantalate network through Ge-O-Ge and Ta-O-Ta bridging bonds. Such structural observations are consistent with the hypothesis of a nanometric scale phase separation between germanate and tantalate networks. Although Raman data hardly bring a complete structural description, one should not that related structural studies performed on tantalum germanate glasses pointed out the formation of these $\mathrm{Ta}_{2} \mathrm{O}_{5}$ clusters in glass compositions with highest tantalum contents at the limit of the glass forming domain resulting in a larger scale phase 
separation and crystalline tantalate precipitation under heat-treatment. $[1,2,38]$ The particularities of such a "new amorphous structure" should be taken into account to describe and then optimize the optical responses of these heavy oxide glasses after thermal poling treatment.

Finally, one should discuss the effect of the voltage magnitude on the induced $\chi^{(2)}$. The $\chi^{(2)}$ increase shows a saturation between 1350 and $2250 \mathrm{~V}$ : $15 \%$ increase whereas the active layer thickness is multiplied by 2 . A simple electrooptical model concludes on a global decrease of the charge density within the poled layer when the applied voltage was increased from $1350 \mathrm{~V}$ to $2250 \mathrm{~V}$. Such behavior should be linked to better charge compensation of the glass matrix upon the sodium depletion formation. Considering poling treatments done under an inert atmosphere and with an inert anode electrode, such saturation effect could be attributed to mechanisms of electronic conduction as proposed by [43] and Zakel $[44](\{\#])]$ and evolving as a function of the applied voltage.

In addition, a deviation from a pure EFISH- $\chi^{(2)}$ tensor has been observed for the sample GNT15-2250. Experimental $\Psi$-scans of the sample poled with the highest voltage are shown in Figure 6 together with three simulations from different optical models. All the models used are based on a $\mathrm{C}_{\infty \mathrm{v}}$ symmetry. The EFISH model considers isotropic refractive indices (as measured for the unpoled glass Figure 2) and impose the ratio $\left.\chi^{(2)_{z z z}} / \chi^{(2)}\right)_{z x x}=3$. The second model named "EFISH/optical anisotropy" on Figure 6, consider that a change of refractive index can occur within the poled layer, inducing an anisotropy between the in-plane and longitudinal indices of the poled layer. The third one keeps the refractive indices unchanged but allows $\chi^{(2)}$ zzz and $\chi^{(2)_{z x x}}$ to be independent values which can be related to possible orientation of dipoles in glasses, as mentioned by Kazansky [11] 
and recently discussed in a paper by Anan'ev [45]. The pure EFISH model overestimates the $\Psi$-p as compared to the $\Psi$-s SHG responses. In this geometry, the $\Psi$-s measurements probe only the "crossed terms" such as $\chi^{(2)_{\mathrm{zxx}}}$, the s-polarized SHG signal corresponds to less than $10 \%$ of maximum SHG intensity. The two other

optical models have improved the correspondence between experiment and simulation but none of these simulations manage to perfectly simulate the experimental response as obtained for the samples poled at lower voltage and an using a EFISH model (see figure 5). The second model converges towards a linear optical anisotropy of $5.10^{-2}$, while the non-EFISH model gives a ratio

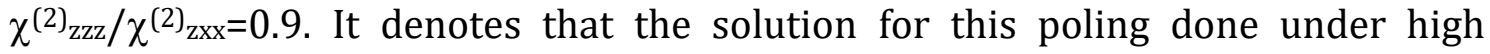
voltage should incorporate both effects: (i) linear optical anisotropy and (ii) a structural $\chi^{(2)}$ response. This could be achieved by careful SHG measurements only if the linear birefringence can be characterized accurately using another method.

\section{5 - Conclusion}

Sodium tantalum germanate glasses were obtained by melt-quenching at high temperature and exhibit a wide optical window from $350 \mathrm{~nm}$ to $5,5 \mu \mathrm{m}$ as well as refractive index ranging from 1.8 to 1.9 depending on the $\mathrm{Ta}_{2} \mathrm{O}_{5}$ content and wavelength. Thermal poling applied in these glasses pointed out that the SHG intensity is strongly dependent on the applied voltage and $\mathrm{Ta}_{2} \mathrm{O}_{5}$ content. For low and intermediate applied voltages, a classical EFISH model was applied to determine the induced second order susceptibility $\chi^{(2)}$. Values around $0.3 \mathrm{pm} / \mathrm{V}$ were obtained for the best experimental conditions. For poling treatment performed using a voltage above $2 \mathrm{kV}$ at $230^{\circ} \mathrm{C}$, a deviation from the EFISH model is 
observed. Linear optical anisotropy and a structural $\chi^{(2)}$ response might have to be taken into account to describe accurately the polarized layer optical properties.

\section{Acknowledgments}

The authors gratefully acknowledge for financial support: IdEx Bordeaux (Cluster of Excellence LAPHIA and Visiting Scholar support) and the CNRS project EMERGENCE@INC2019. Facilities from the platform SIV.

This project has received funding from the European Union's Horizon 2020 research and innovation programme under the Marie Skłodowska-Curie grant agreement No 823941 (FUNGLASS). This article reflects only the author's view and that the Agency is not responsible for any use that may be made of the information it contains.

\section{References}

[1] G.M. De Pietro, C. Pereira, R.R. Gonçalves, S.J.L Ribeiro, C.D. Freschi, F.C. Cassanjes, G. Poirier. Thermal, structural and crystallization properties of new tantalum alkali-germanate glasses. J.Am.Cer.Soc., 1-8 (2015).

[2] C.R. da Cunha, S.A. Maestri, B.P. de Sousa, L.M. Marcondes, R.R. Gonçalves, F.C. Cassanjes, G. Poirier. Alkali metal tantalum germanate glasses and glassceramics formation. J.Non-Cryst.Sol. 499 (2018) 401-407.

[3] L.M. Marcondes, S.A. Maestri, B.P. de Sousa, R.R. Gonçalves, F.C. Cassanjes, G. Poirier. High niobium oxide content in germanate glasses: thermal, structural and optical properties. J.Am.Cer.Soc., 101 (2018) 220-230. 
[4] Y. Quiquempois, N. Godbout, S. Lacroix. Model of charge migration during thermal poling in silica glasses: Evidence of a voltage threshold for the onset of a second-order nonlinearity. Phys.Rev.A, 65-4 (2002) 043816(B).

[5] X. Liu, M. Zhang. Theoretical study for thermal/electric field poling of fused silica. Jap.Journal.Appl.Phys. 40 (2001) 4069-4076.

[6] M. Dussauze, T. Cremoux, F. Adamietz, V. Rodriguez, E. Fargin, G. Yang, T. Cardinal. Thermal poling of optical glasses: mechanisms and second-order optical properties. Int.Journal.Appl.Glass.Sci. 3 (2012) 309-320.

[7] A Lepicard, F Bondu, M Kang, L Sisken, A Yadav, F Adamietz, V. Rodriguez, K. Richardson, M. Dussauze. Long-lived monolithic micro-optics for multispectral GRIN applications. Scientific reports 8 (2018) 7388.

[8] L. A. H. Fleming, D. M. Goldie, and A. Abdolvand. Imprinting of glass. Opt. Mater. Express 5 (2015) 1674-1681.

[9] A. A. Lipovskii, V. V. Rusan, and D. K. Tagantsev. Imprinting phase/amplitude patterns in glasses with thermal poling. Solid State Ionics 181 (2010) 849-855. [10] R.A. Myers, N. Mukherjee, S.R.J. Brueck. Large 2nd-order nonlinearity in poled fused-silica. Opt.Lett. 16 (1991) 1732.

[11] P.G. Kazansky, PS.J. Russel. Thermally poled glass-Frozen-in electric field or oriented dipoles. Opt.Commun. 110 (1994) 611.

[12] N. Mukherjee, R.A. Myers, S.R.J. Brueck. Dynamics of second-harmonic generation in fused silica. J.Opt.Soc.Am.B 11 (1994) 665.

[13] G. Li, K.A. Winick, A.A. Said, M. Dugan, P. Bado. Quasi-phase matched secondharmonic generation through thermal poling in femtosecond laser-written glass waveguides. Opt.Express 17 (2009) 9442. 
[14] A. Strauss, U. Jauernig, V. Reichel, H. Bartelt. Generation of green light in a thermally poled silica fiber by quasi-phase matched second harmonic generation. Optik (Jena) 121 (2010) 490.

[15] M. Dussauze, V. Rodriguez, A. Lipovskii. How does thermal poling affect the structureof soda-lime glass? J.Phys.Chem.C 114-29 (2010) 12754-12759.

[16] H. Nasu, H. Okamoto, K. Kurachi. 2nd-harmonic generation from electrically poled $\mathrm{SiO} 2$ glass-Effects of $\mathrm{OH}$ concentration, defects, and poling conditions. J.Opt.Soc.am.B 12-4 (1995) 644-649.

[17] H. An, S. Fleming. Second-order optical nonlinearity and accompanying near-surface structural modifications in thermally poled soda-lime silicate glasses. J.Opt.Soc.Am.B 23-11 (2006) 2303-2309.

[18] M. Dussauze, E. Fargin, M. Lahaye, V. Rodriguez, F. Adamietz. Large secondharmonic generation of thermally poled sodium borophosphate glasses. Opt.Express 13-11 (2005) 4064.

[19] M. Dussauze, E. Fargin, A. Malakho, V. Rodriguez, T. Buffeteau, F. Adamietz. Correlation of large SHG responses with structural characterization in borophosphate niobium glasses. Opt.Mat. 28 (2006) 1417-1422.

[20] M. Dussauze, E.I. Kamitsos, E. Fargin. Structural rearrangements and second-order optical response in the space charge layer of thermally poled sodium-niobium borophosphate glasses. J.Phys.Chem.C 111-39 (2007) 1456014566.

[21] P. Thamboon, D.M. Krol. Second-order optical nonlinearities in thermally poled phosphate glasses. J.Appl.Phys. 93-1 (2003) 32-37.

[22] K. Tanaka, K. Kashima, K. Hirao. 2nd-harmonic generation in electrically poled Li20-Nb205-Te02 glasses. J.Non.Cryst.Sol. 185, 1-2 (1995) 123-126. 
[23] K. Tanaka, A. Narazaki, K. Hirao. Large optical second-order nonlinearity of poled W03-Te02 glass. Opt.Lett. 25-4 (2000) 251-253.

[24] G.S. Murugan, E. Fargin, V. Rodriguez. Temperature-assisted electrical poling of Te02-Bi203-ZnO glasses for non-linear optical applications. J.Non.Cryst.Sol. 344-3 (2004) 158-166.

[25] M. Guignard, V. Nazabal, J. Troles. Second-harmonic generation of thermally poled chalcogenide glasses. Opt.Express 13-3 (2005) 789-795.

[26] M. Guignard, V. Nazabal, F. Smektala. High second-order non linear susceptibility induced in chalcogenide glasses by thermal poling. OptExpress $14-4$ (2006) 1524-1532.

[27] A. Lepicard, F. Adamietz, V. Rodriguez. Demonstration of dimensional control and stabilization of second harmonic electro-optical response in chalcogenide glasses. Opt.Mat.Express 8-6 (2018) 1613-1624.

[28] G. Guimbretière, M. Dussauze, V. Rodriguez, E.I. Kamitsos. Correlation between second-order optical response and structure in thermally poled sodium niobium-germanate glass. Appl.Phys.Lett. 97 (2010) 171103.

[29] H. Nasu, Y. Ito, Y. Yamamoto. Second harmonic generation from thermally poled Pb0-Ge02 glasses. J. Cer.Soc.Jap. 109-4 (2001) 366-368.

[30]C. Bahrim, W.T. Hsu. Precise measurements of the refractive índices for dielectrics using an improved Brewster angle method. Am.J.Phys. 77-4 (2009) $337-343$

[31] V. Rodriguez, C. Sourisseau. General Maker-fringe ellipsometric analyzes in multilayer nonlinear and linear anisotropic optical media. J.Opt.Soc.Am.B $19-11(2002) 2650$. 
[32] J. Ferrari, K.O. Lima, L.J.Q. Maia. Structural and spectroscopic properties of luminescent Er3+-doped Si02-Ta205 nanocomposites. J.Am.Cer.Soc. 94-4 (2011) 1230-1237.

[33] G.S. Henderson, M.E. Fleet. The structure of glasses along the Na20-Ge02 join. J.Non.Cryst.Sol. 134 (1991) 259-269.

[34]G. Monteiro, L.F. Santos, J.C.G. Pereira, R.M. Almeida. Optical and spectroscopic properties of germanotellurite glasses. J.Non.Cryst.Sol. 357 (2011) 2695-2701.

[35] C. Joseph, P. Bourson, M.D. Fontana. Amorphous to crystalline transformation in Ta205 studied by Raman spectroscopy. J.Raman.Spect. 43-8 (2012) 1146-1150.

[36] T. Tsuchiya, H. Imai, S. Miyoshi. X-Ray absorption, photoemission spectroscopy and Raman scattering analysis of amorphous tantalum oxide with a large extent of oxygen nonstoichiometry. Phys.Chem.Chem.Phys. 13-38 (2011) 17013-17018.

[37] J. Peng, J. Cao, L. Tan, M. Peng. Glass-forming region and enhanced Bi NIR emission in sodium tantalum silicate laser glass. J.Am.Cer.Soc. 102 (2019) $2522-2530$.

[38] K.M. Wetherall, P. Doughty, G. Mountjoy, M. Bettinelli, A. Speghini, M.F. Casula, F. Cesare-Marincola, E. Locci, R.J. Newport. The atomic structure of niobium and tantalum containing borophosphate glasses. J.Phys.Cond.Mat. 21 (2009) 375106.

[39] T. Cardinal, E. Fargin, G. Le Flem, S. Leboiteux. Correlations between structural properties of Nb205-NaP03-Na2B407 glasses and non-linear optical activities. J. Non-Cryst. Solids 222 (1997) 228. 
[40] T. Cardinal, E. Fargin, G. Le Flem, et al. Non linear optical properties of some niobium(V) oxide glasses. Eur. J. Solid State Inorg. Chem. 33-7 (1996) 597.

[41] A.A. Lipovskii, D.K. Tagantsev, A.A. Vetrov, O.V. Yanush. Raman spectroscopy and the origin of electrooptical Kerr phenomenon in niobium alkali-silicate glasses. Opt. Mater. 21 (2003) 749.

[42] M. Dussauze, E. I. Kamitsos, E. Fargin, V. Rodriguez. Refractive index distribution in the non-linear optical layer of thermally poled oxide glasses. Chem. Phys. Lett. 470 (2009)63-66.

[43] U. K. Krieger, W.A.Lanford. Field assisted transport of $\mathrm{Na}+$ ions, Ca2+ ions and electrons in commercial soda-lime glass I: Experimental. J. Non-Cryst. Solids 102 (1988) 50-61.

[44] J. Zakel, M. Balabajew, B. Roling. On the mechanism of field-induced mixed ionic-electronic transport during electro-thermal poling of a bioactive sodium-calcium phosphosilicate glass. Solid State Ionics 265 (2014) 1-6.

[45] A. V. Anan'ev, A. A. Lipovskii, D. K. Tagantsev. Is frozen space charge responsible for SHG in poled silicate glasses only?. J. Non-Cryst. Solids 458 (2017) 118-120. 
Table 1. Glass compositions, poling voltage and $\chi^{(2)}$ values.

\begin{tabular}{|c|c|c|c|c|c|}
\hline \multicolumn{3}{|c|}{ Composition (mol \%) } & Sample & Poling voltage & $\chi^{(2)}$ \\
\cline { 1 - 3 } $\mathrm{GeO}_{2}$ & $\mathrm{Na}_{2} \mathrm{O}$ & $\mathrm{Ta}_{2} \mathrm{O}_{5}$ & & & \\
\hline 75 & 10 & 15 & GNT15-900 & $900 \mathrm{~V}$ & $0,06 \mathrm{pm} / \mathrm{V}$ \\
\hline 75 & 10 & 15 & GNT15-1350 & $1350 \mathrm{~V}$ & $0,2 \mathrm{pm} / \mathrm{V}$ \\
\hline 75 & 10 & 15 & GNT15-2250 & $2250 \mathrm{~V}$ & $0,23 \mathrm{pm} / \mathrm{V}$ \\
\hline 70 & 10 & 20 & GNT20-1350 & $1350 \mathrm{~V}$ & $0,3 \mathrm{pm} / \mathrm{V}$ \\
\hline
\end{tabular}




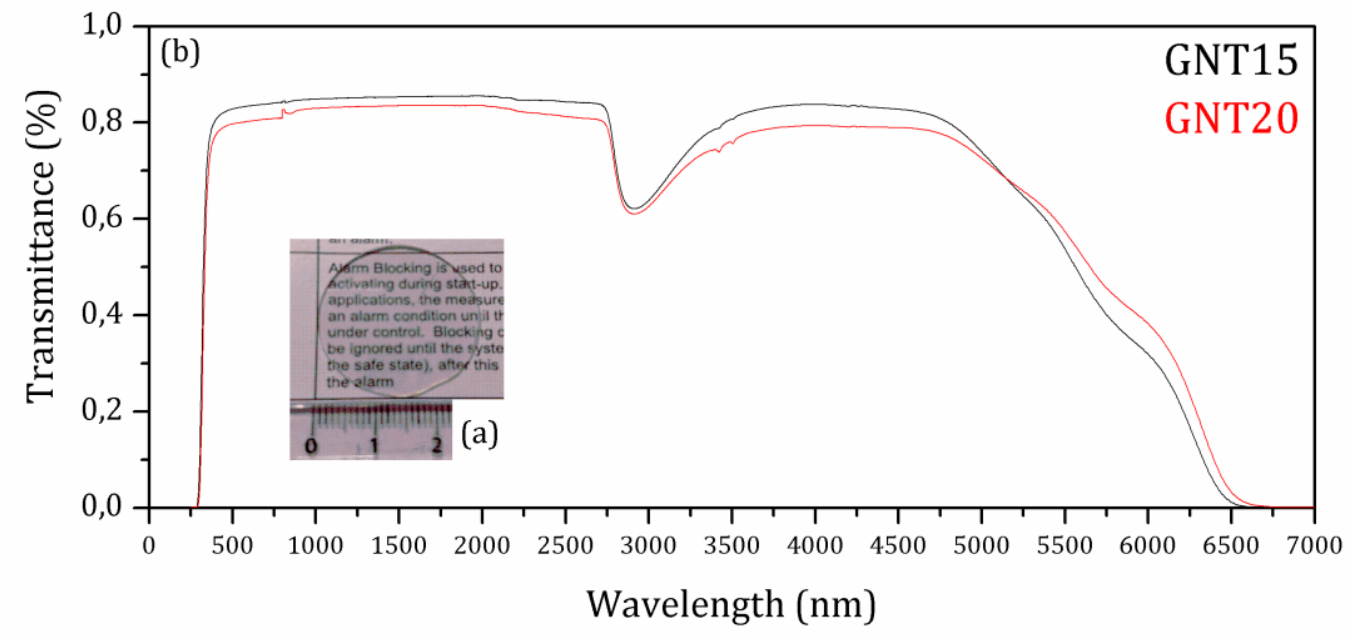

Figure 1

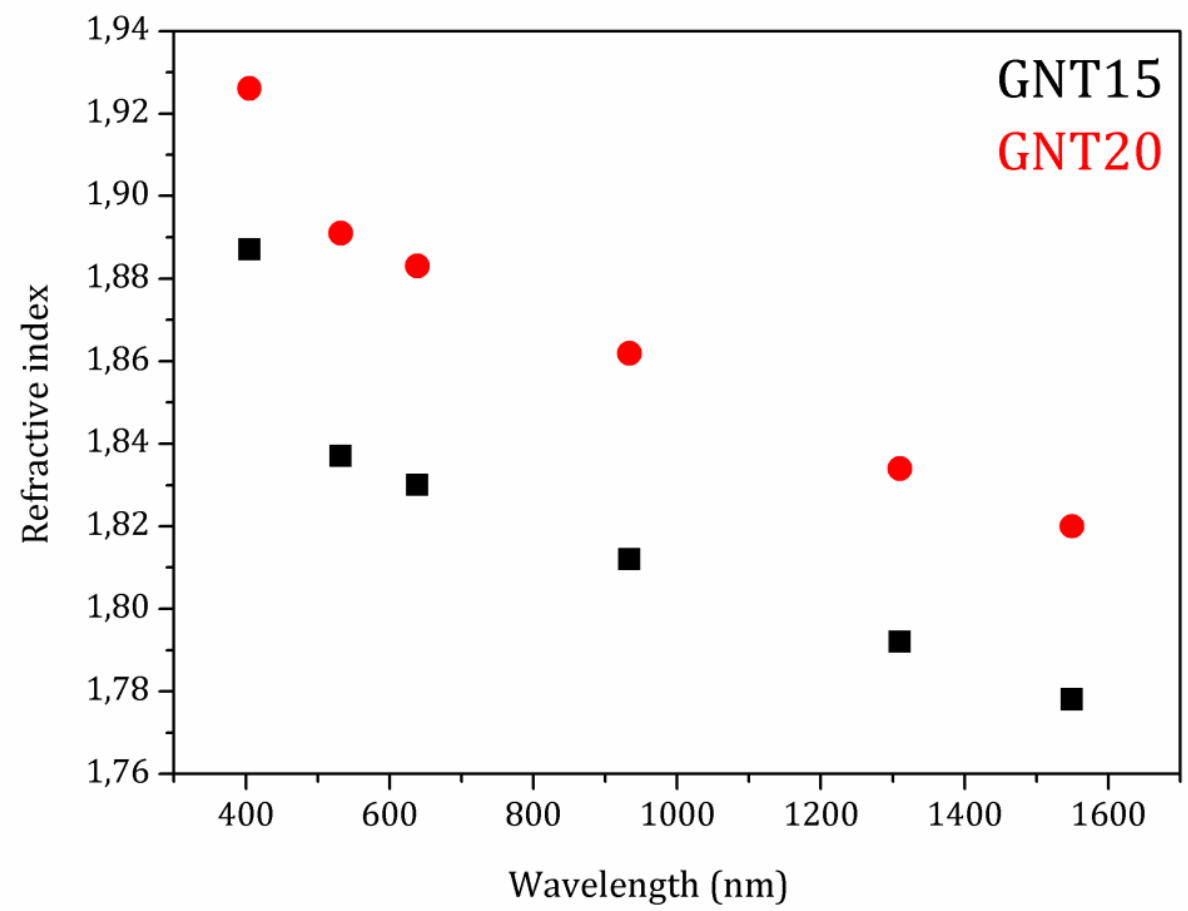


Figure 2

(A)

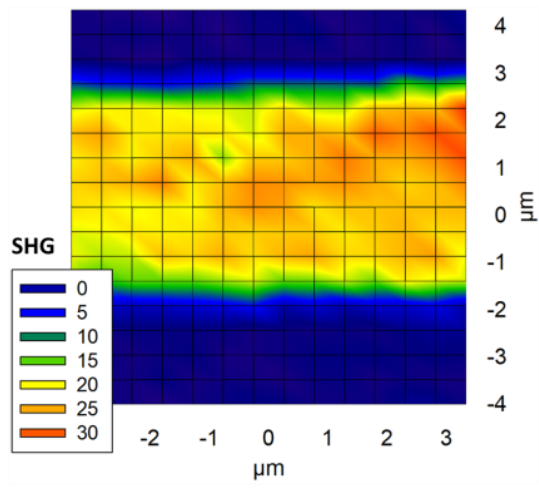

(B)

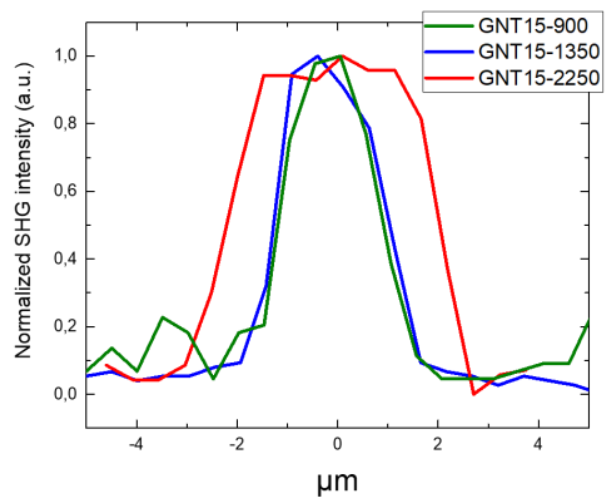

Figure 3 

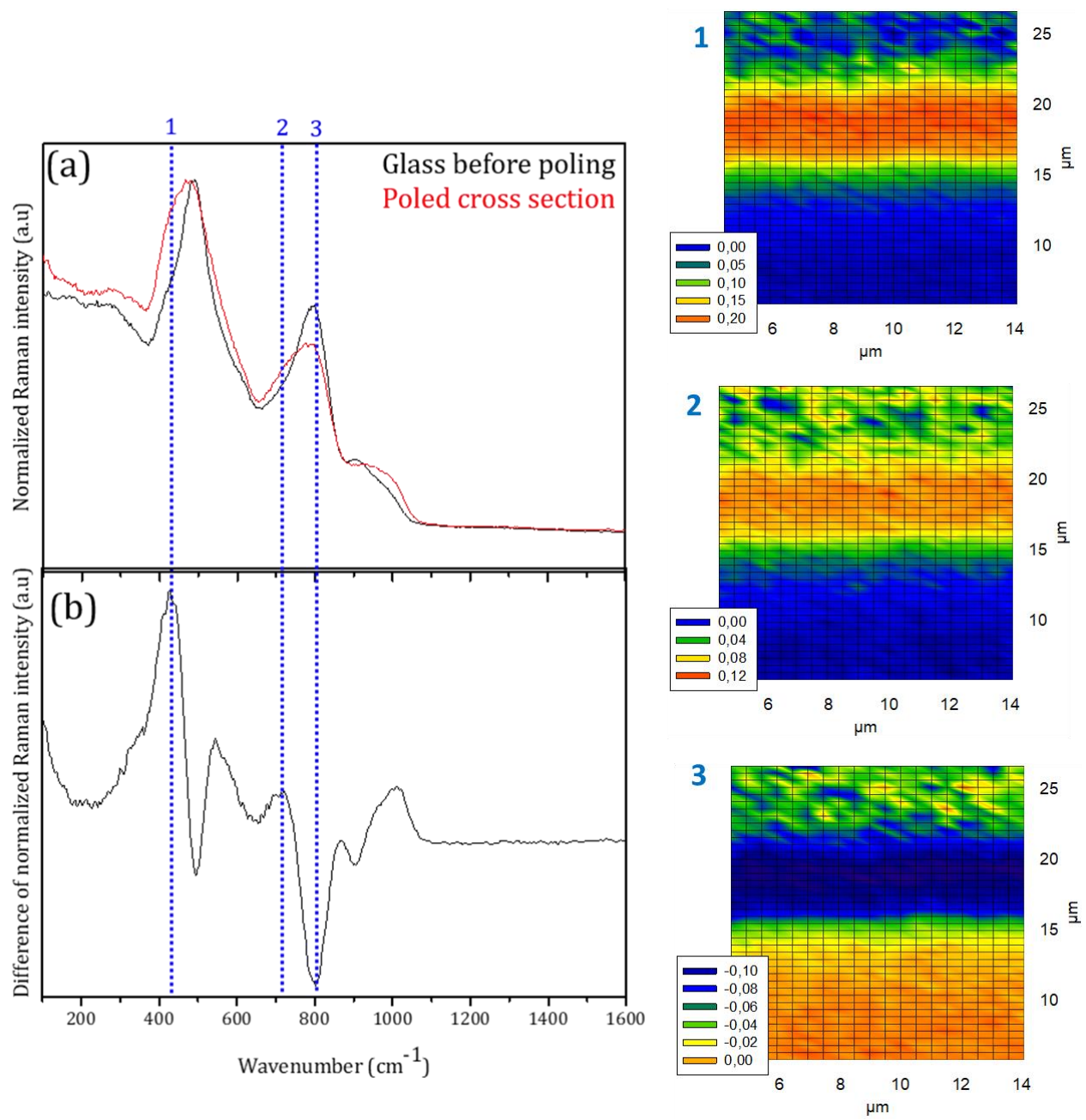

Figure 4 

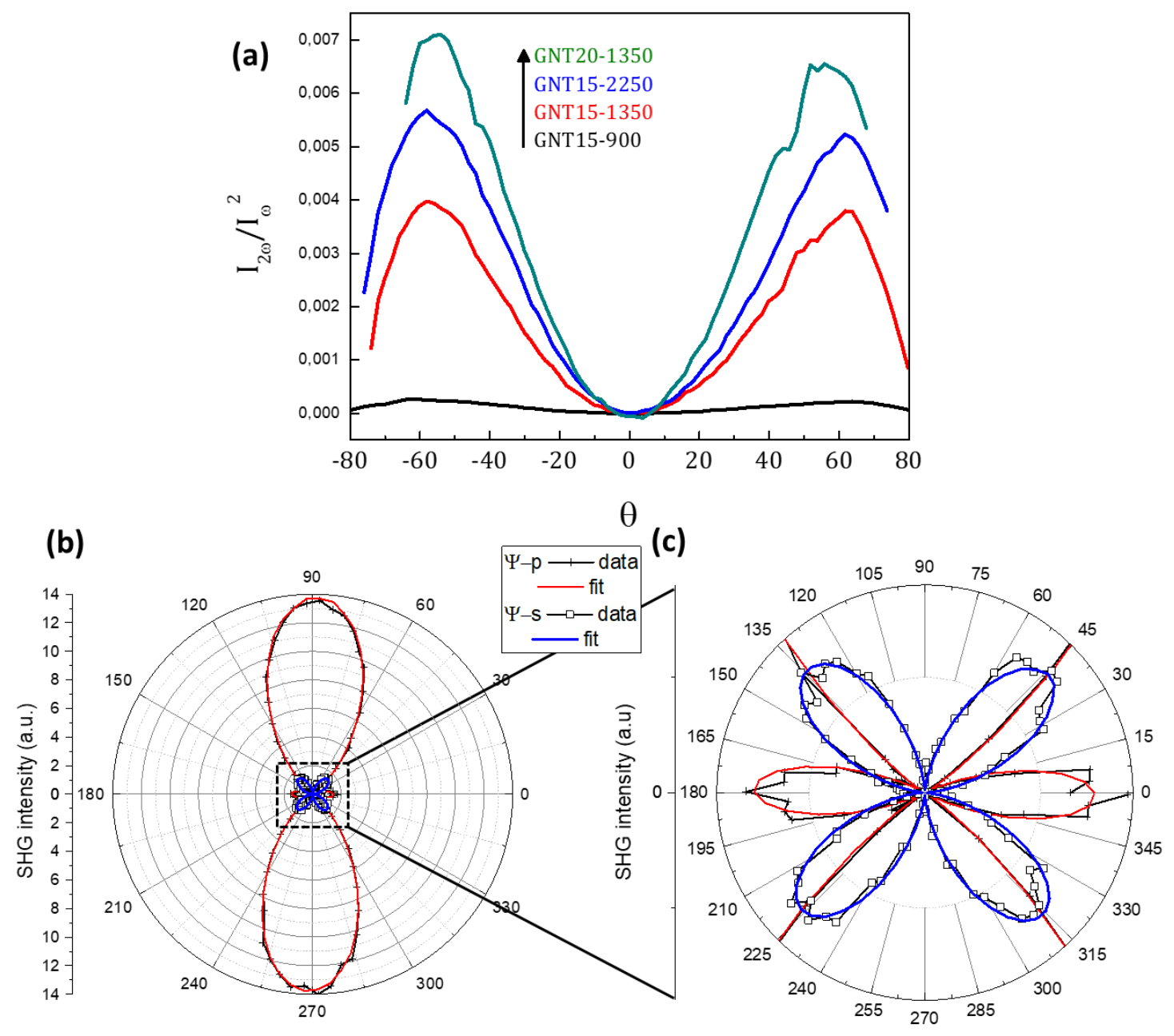

Figure 5 


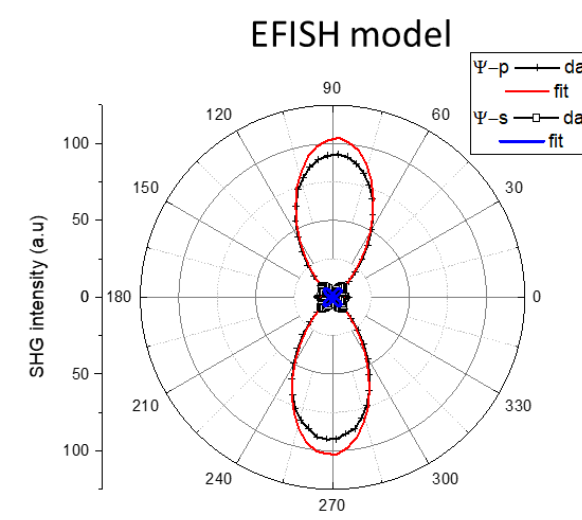

\section{EFISH model / Opical anisotropy}

Non-EFISH model
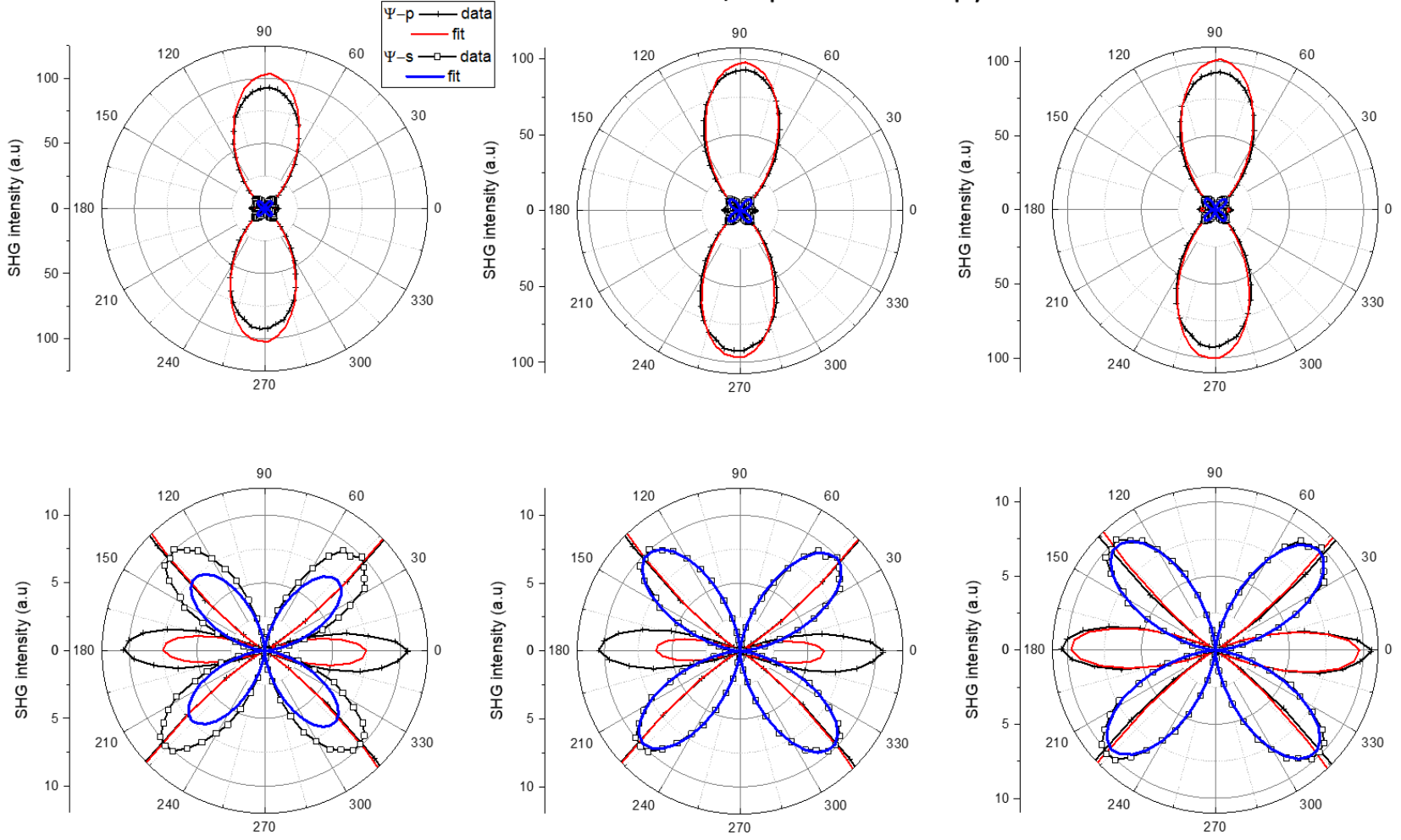

Figure 6

\section{Figure Captions}

Figure 1. (a) Optical window of glass samples GNT15 and GNT20 and (b) visual aspect of glass sample GNT15 .

Figure 2. Refractive index dispersion of glass samples GNT15 and GNT20. 
Figure 3. (A) SHG mapping of the GNT15 poled cross section after thermal poling at 2250V. (B) Comparison of SHG intensity profiles for a GNT15 composition as a function of the poling voltage measured in the poled cross-section.

Figure 4. (Left) Raman spectra of sample GNT15 before poling and in the poled cross section after poling at 2250V (a) and Raman intensity difference spectra before and after poling (b). (Right) Raman intensity mapping of three specific Raman modes at $430 \mathrm{~cm}^{-1}, 710 \mathrm{~cm}^{-1}$ and $800 \mathrm{~cm}^{-1}$.

Figure 5. Macro-SHG measurements on GNT15 thermally poled at 1350V (a) SHG measurements as a function of the incident angle with a fixed P-polarization state for both incident beam and detected SHG, and (b) as a function of the incident polarization state with a fixed incident angle of $60^{\circ}$ and either a $\mathrm{P}$ - or a $\mathrm{S}$ polarization detection (respectively $\Psi-\mathrm{P}$ and $\Psi-S$ ). (c) shows a zoom of the central part of figure (b).

Figure 6. Macro-SHG measurements and simulations performed on sample GNT15 thermally poled at $2250 \mathrm{~V}$ using a classical EFISH model, an EFISH model with optical anisotropy and a non-EFISH model. 